\title{
Achieving National Recognition Through Experiential Learning
}

\author{
Stephen R. Lucas, (E-mail: SRLucas@uncg.edu), University of North Carolina, Greensboro \\ Norwood McMillian, (E-mail: N_Mill@ uncg.edu), University of North Carolina, Greensboro \\ Benton E. Miles, (E-mail: BEMiles@uncg.edu), University of North Carolina, Greensboro
}

\begin{abstract}
A student marketing organization was created as an internship project sponsored by General Motors $(G M)$. Students gained hands-on experience in marketing the products and services of a local General Motors dealership selected by GM. The finalist team members presented the results of the project to a panel of GM representatives. The plan and its implementation which resulted in first place in a nationwide competition will be discussed. This paper will evaluate the project and determine the benefits to students, the faculty member, the University, and the community.
\end{abstract}

\section{INTRODUCTION}

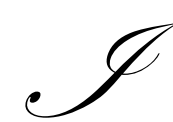

$\mathrm{n}$ an effort to acquire knowledge and experience, the students in the organization were given the opportunity to offer a research service to a client from the local community, while also increasing campus awareness of the client's products and services. The knowledge obtained by students will enhance them as they enter the workforce and the experience will aid the students in competing for positions in marketing. The service provided to the client is invaluable because of the pertinent information that was gained about college-age students and the exposure that was gained from the promotional campaign activities.

\section{THE CHARGE TO THE STUDENTS}

The University of North Carolina at Greensboro's (UNCG) marketing faculty want students to know more than just the material found in a book. A GM dealership, EdVenture Partners, and General Motors provided UNCG's marketing program with the opportunity to set up an internship wherein students could create their own marketing agency and work for a real client, with a real product. The purpose of the internship is to help students gain first-hand experience with promotion management. The students in the class designed a structure to duplicate the inner workings of an authentic marketing firm; the project was segmented into six, distinctive departments: Advertising, Budget, Publications, Public Relations, Event Day, and Research.

In order to sense the spirit and the challenge of the project, here is an excerpt from an announcement made by the student coordinator of the project to the students in a marketing class where the project was being implemented:

Alive for the Drive will be held on Wednesday, April 14. The local GM dealership is funding student marketing teams with a budget to partially support the promotional campaign. The marketing team will have students, faculty, and community members, totaling at least 1,500, in attendance at a planned campaign event. The objective of the campaign is to increase student awareness and improve the perception of a GM brand by promoting its products and services.

A critical ingredient of such an undertaking is for the instructor to instill a sense of ownership on the part of the students. The instructor becomes a project adviser, but is not a participant in the project. The instructor, in a sense, is both an outside observer and consultant. The instructor's goal should be that the students feel that this is their project and not just another course assignment. 


\section{ORIENTATION TO THE PROJECT}

The students were challenged to convince the market segment of 18 to 30 year-old students that they could move from a college lifestyle of complete freedom into the professional world of responsibility and restriction while, at the same time, keeping their individuality. The campaign was directed toward showing the students a particular GM brand and to convince them that "work" does not mean the elimination of "fun." Further, the campaign proposed that a GM car could provide the individuality and the fun.

\section{CREATING THE STRUCTURE OF THE INTERNSHIP}

The students created an organizational chart depicting six departments - Advertising, Budget, Publications, Public Relations, Research, and Event Day. Each department determined the appropriate goal and objectives for its mission.

\section{Organizational Chart}

The organization consisted of the following titles and deployment of students: One coordinator, two cocoordinators, six department heads, six assistants to department heads, and thirty students assigned to support the departments (six with advertising, two with budgeting, three with publications, two with public relations, seven with research, and ten with event day).

\section{Advertising}

Goal

Increase awareness of the GM brand to be promoted.

Objectives

Create awareness of GM, GMAC, and local dealer promotions for sales and financing.

Create traffic for the promotional event activities.

Positively influence students' perception of the GM brand.

\section{Budget}

Goal

To create a budget and track the deposits as well as the allocation of all expenses incurred by all departments.

Objectives

Track cost and value of all purchases and donations.

Organize financial receipts received from various departments.

Record expenses into expense log.

Complete a budget report.

Manage event-day inventory to include prizes, donations, games, and miscellaneous.

Create guidelines for the organization to follow to ensure adequate resources.

Predict a budget plan in order to attain campaign goals.

\section{Publications}

Goal

Create print material to define and communicate the marketing intention, the approaches to the target market, and the accomplishments to satisfy the individual and organization.

\section{Objectives}

Document all campaign activities. 
Document all meetings (e.g., focus groups).

Produce all campaign materials (e.g., a pre-event brochure).

Create a strategy booklet (final product).

\section{Public Relations}

\section{Goal}

To inform the UNCG community about the event while developing relationships with campus media, community media, UNCG's public information office, and local businesses.

Objectives

Plan a publicity strategy.

Develop relationships to include press releases, invite guests, and thank-you letters.

Develop media kits.

\section{Research}

Goal

Conduct valid and reliable market research of the target market specified by the GM dealer.

\section{Objectives}

Use proper sampling techniques to produce a representative sample of the target market.

Create and conduct pre-event and post-event surveys and conduct focus groups.

Analyze data.

Distribute appropriate information to other departments.

\section{Event Day}

\section{Goal}

Promote the GM product through participant interaction.

\section{Objective}

Plan and implement the promotion campaign.

Create event layout for placement of games, cars, tables, etc.

Create games and corresponding rules for participation.

Design event-day schedule.

Contact vendors and obtain the necessary insurance permits.

Create a menu for the event.

Determine prize distribution.

Design registration forms.

\section{TARGET MARKET}

The target market was the UNCG community, but there was a particular interest in one segment of the student population - students who were 18 to 30 years of age. This college-age group is well-represented on the UNCG campus. In general, the student body is 14,000 students. In-state students represent $91.9 \%$ of undergraduates with $8.1 \%$ in the out-of-state category. Females comprise approximately two-thirds of the population at UNCG while males constitute the remainder.

\section{LIAISONS FOR THE PROJECT}

EdVenture Partners facilitates innovative alliances between the local business community and a higher education institution that further the growth of both types of entities. Since its inception in 1991, EdVenture has 
designed and managed programs at high schools, colleges, and universities across the county. Representatives of EdVenture Partners were available for consultation throughout the course.

\section{IMPLEMENTATION}

There were many decisions to be made in this kind of project. In addition to creating an organization chart identifying departments/personnel and statements of departmental goals and objectives, a project timeline was needed. Below is the project timeline for the campaign.

Week of February 2 Site visit to dealership.

Week of February 9 Design surveys and obtain approval. Obtain sponsorship information.

Week of February 16 Distribution of surveys. Collect survey at end of the week. Conduct analysis.

Week of February 23 Advertising implementation. Prepare for pre-event presentation.

Week of March 1 Prepare for pre-event presentation/ pamphlet and all material needed for the Publications

Department.

Week of March $5 \quad$ UNCG Spring Break - no classes.

Week of March 15 Rehearse the pre-event presentation.

Week of March 22 Continue to rehearse the pre-event presentation.

Week of March 29 The official pre-event presentation.

Week of April $5 \quad$ Event Day preparation - to include banners, cars, games, surveys, banners, and T-shirts.

Week of April $12 \quad$ Event Day will be held on April 14.

Week of April $19 \quad$ Post-event survey distribution and analysis of post-event surveys.

Week of April $26 \quad$ Prepare for the final presentation and report.

Week of May $3 \quad$ Practice presenting the final presentation.

Week of May 10 Final presentation to members of General Motors Management Institute and the local dealership.

\section{SOLICITING FUNDS FOR THE EVENT}

The students were given a beginning budget of $\$ 2,500$ by GM. The budget challenge was for the students to raise additional monies needed to carry out their planned activities. Through a variety of means (raffling donated products, a car wash for donations; cash donations from businesses; and money received in exchange for T-shirt ads, flyer-ads, and website ads), the students received 68 donations which were estimated to be sufficient to defray the expenses for the project.

\section{EVENT SCHEDULE}

The event schedule is the schedule for the main event - Event Day. Here is the time schedule for the day of the main event. Several thousand people from the University as well as from the community-at-large participated in the event.

6:00 a.m. Begin with the setup plan. Bring in the cars.

7:00 a.m. Games delivered and set up. Dunking booth training session.

7:30 a.m. Set up the pizza and beverage tables.

8:00 a.m. Training session for rules. Breakfast.

9:00 a.m. Event Day kickoff. Registration begins.

10:00 a.m. First radio van (campus radio - 10:00 a.m. to 12:00 noon). Hourly drawing begins.

10:15 a.m. Hourly game begins - Trivia game.

11:00 a.m. Pizza brought out in 30-minute intervals. Car survivor begins. Hourly drawing.

11:15 a.m. Hourly game - Pie eating contest.

12:00 p.m. Second radio van (Station 102.1 FM - 12:00 p.m. to 2:00 p.m.). Hourly drawing.

12:15 p.m. Hourly game - Trivia game.

1:00 p.m. Hourly drawing. 
1:15 p.m. Hourly game - Pie eating contest.

2:00 p.m. Third radio van (Station 94.5 FM - 2:00 p.m. to 4:00 p.m.) Grand Prize Drawing.

2:15 p.m. Hourly game - Bobbing for cars.

3:00 p.m. Hourly drawing.

3:15 p.m. Hourly game - Pie eating contest.

4:00 p.m. Super Grand Prize Drawing.

4:15 p.m. $-6: 15$ p.m. Clean the site location. Cars driven back to the dealership.

\section{RESULTS}

The team report for the post-event survey showed a double-digit increase in recognition of the brand when compared to the pre-event survey result. Also, the post-event survey revealed that there was a $125 \%$ increase in recognition of the name of the local GM dealer when compared to the pre-event survey data. A final result of the event was that respondents in the post-event portion of the study were more positively responsive to the featured car.

\section{TEAM PRESENTATION}

The project team culminated the internship by presenting the results both in writing and orally. The judges for this competition were the GM area manager, an EdVenture Partner representative, the dealership manager, and the dealership sales manager. The duration of the presentation was 75 minutes. After the local presentation, each campaign booklet, a video tape of the presentation, and a video tape of the Event Day are sent to GM's regional office in Atlanta. At this point, all campaigns are evaluated and two are selected for the final competition. The expenses of each of the two university teams (and the professors) are defrayed by GM in order that they can participate in the national competition in Atlanta.

The UNCG professor, who has incorporated this internship project in his course for the past seven years, has been successful in that his class has completed campaigns that have brought acclaim to the marketing program and the students highly value the internship experience. Recently, his students' campaigns have received first place in two years consecutive years. The professor contends that this activity blends theory with practice and results in a perfect situation whereby students are rewarded for their ability to apply knowledge in a real-world environment.

\section{BENEFITS TO THE UNIVERSITY/SCHOOL OF BUSINESS}

\section{Funding}

Discretionary funding is provided by GM via EdVenture Partners. The activity provides discretionary funding for the Department in a time of limited resources. "Discretionary" dollars are more valuable than "state" dollars because they are more flexible - fewer limitations are placed on how they can be spent and these dollars do not revert at the end of the fiscal year.

\section{Community Relationships}

This marketing internship develops closer ties with local businesses and the University. At a later date, this relationship, could blossom into a larger contribution to the university or school to enhance the university or school mission.

\section{Recruiting of On-Campus Majors}

The marketing internship can assist schools of business in recruiting new business majors from the university population. The "undecided" group of students presents a fertile ground for recruitment. Students in this undecided group could likely participate in the student interaction part of the Event Day activities. This participation could interest the undecided student in exploring the marketing major offering. 


\section{Recruiting of International Students}

The internship program aspect of the course is especially appreciated by international students. The international students have indicated that the certificate from GM recognizing their participation in the internship effort is valued by future employers in their native country. In addition, participation in this internship makes it easier to recruit international students from their home institution of higher education.

\section{Faculty Recognition}

This internship activity is valued by most universities because of the positive relationship it develops with the business community. In addition, it provides the faculty member opportunities for research leading to publications.

\section{BENEFITS TO THE STUDENTS}

\section{Networking}

This internship affords the students an opportunity to network with business executives. The students meet with the regional GM executive and the local GM executives throughout the project.

\section{Resume Enhancemen}

The internship affords the students an opportunity to enhance their resumes (GM Certificate of participation recognizing the marketing internship). Employers visiting the campus want to know what the student has done; a lesser emphasis is placed on the classes the student has completed. Participation in the project provides a concrete example of what the student is capable of doing.

\section{Real-World Experience}

It provides the students an opportunity to participate in a real-world experience. The students develop and implement a strategy that addresses a marketing opportunity.

\section{Career Opportunities}

This activity encourages local businesses to seek future marketing employees from the Bryan School of Business and Economics. Illustrative of this student benefit was a local businessperson who contacted the professor and announced that the firm was looking for three potential employees who have participated in the internship effort. The employer indicated that the starting annual salary would be $\$ 60,000$ (this is well-above the starting salary level for this geographic area).

\section{BENEFITS TO THE BUSINESS}

\section{Research Information}

The campaign assists the business in penetrating the target market. For instance, the dealership did not previously have access to the information reported in the strategy booklet (final project).

\section{Employee Recruitment}

The effort permits the business to network with a talent pool. This internship provided ample opportunity for the business partner to evaluate the talents of individual participants. 


\section{POTENTIAL PITFALLS}

There are a number of concerns that the faculty member should consider before deciding to participate in the GM internship program as part of a class. Here are five concerns:

- $\quad$ This project is time-consuming. The professor needs to set aside additional time for the project beyond the amount of time one would budget for a traditional class. The internship is not a recommended activity for nontenured, tenure-track faculty.

- It is easier to control the educational process in a traditional class setting (four-walls setting) than in an experiential learning environment that involves outside considerations. This project requires that students travel throughout the community as individuals or in small groups and the professor will not or cannot accompany the students on all occasions. Thus, the professor is not privy to the totality of the experience.

- The students have the potential to embarrass the university and school in the business community. Successful interaction between students and business people requires that students display professionalism (e.g., tact, appropriate dress, and personal conduct).

- $\quad$ There is difficulty in judging individual student performance. Students are assigned to departments that comprise the organization of the campaign; departments (teams) are evaluated by the professor and fellow team members.

- It takes a special faculty member to be successful in this type of project. The faculty member should not be assigned the project but, instead, should want to embrace the project as a desirable class project. The Department Head could be instrumental, in this regard; the Head could be the impetus in selecting the faculty member and presenting the opportunity. 


\section{NOTES}

